Berkers, Pauwke, Susanne Janssen and Marc Verboord. 2010. Assimilatie in de literaire mainstream? Etnische grenzen in dagbladrecensies van etnische minderheidsauteurs in de Verenigde Staten, Nederland en Duitsland. Mens \& Maatschappij 85(3):284-313.

http://www.ingentaconnect.com/content/aup/mem/2010/00000085/00000003/art00005

\title{
Assimilatie in de literaire mainstream? \\ Etnische grenzen in dagbladrecensies van etnische minderheidsauteurs in de Verenigde Staten, Nederland en Duitsland
}

Pauwke Berkers (berkers@eshcc.eur.nl)

Department of Art and Culture Studies (ESHCC), Erasmus University Rotterdam, the

Netherlands

\section{Susanne Janssen}

\section{Marc Verboord}

\begin{abstract}
This article addresses to what extent literary critics in the United States, the Netherlands and Germany have drawn ethnic boundaries in their reviews of ethnic minority writers between 1983 and 2009 and to what extent ethnic boundaries in literary criticism have changed in each country in the course of ethnic minority writers' careers and across time. By analyzing newspaper reviews, we find that American reviewers less often mention the ethnic and/or majority background of Mexican American authors than their Dutch and German colleagues refer to the background of Moroccan and Turkish minority writers. But while these relatively strong ethnic boundaries become weaker over time in the Netherlands, Turkish German authors encounter particularly strong boundaries in subsequent book publications. In the U.S. the reverse is true: ethnic boundaries weaken after the debut has been reviewed.
\end{abstract}




\section{Inleiding}

Participatie in culturele activiteiten, zowel productief als receptief, verschilt in Westerse samenlevingen sterk langs lijnen van sociale stratificatie (Bennett e.a., 2008; Bourdieu, 1984 [1979]; Roose \& Waege, 2003; Van Eijck, De Haan \& Knulst, 2002). Recentelijk zijn sociologen zich steeds meer gaan richten op de symbolische - in plaats van de sociale - dimensies van culturele praktijken. Symbolische grenzen, dat wil zeggen conceptuele classificaties om objecten, mensen, praktijken, en zelfs tijd en ruimte te categoriseren (Lamont \& Molnár, 2002) zijn aanwezig in elk sociaal domein (zoals arbeid, religie, kunst) en kunnen betrekking hebben op alle types groepsgebaseerde classificaties (zoals klasse, gender, etniciteit). Dit artikel handelt over de symbolische grenzen waar etnische minderheidsauteurs mee te maken kunnen krijgen wanneer zij zich in het domein van de hoge cultuur begeven. Daarbij combineren we twee sociologische stromingen die de afgelopen decennia op vruchtbare wijze onderzoek hebben verricht naar symbolisch grenzen, namelijk de sociologie van kunst en cultuur en die van etniciteit.

Cultuursociologisch onderzoek naar symbolische grenzen belicht vooral hoe de classificatie van kunst leidt tot de productie van symbolische waarde en culturele hiërarchieën (Baumann, 2001; Baumann, Dowd \& Janssen, 2009; DiMaggio, 1987). Voortbouwend op Bourdieu's werk (1984 [1979]) is veel onderzoek verricht naar culturele classificaties ('distinctie') als de producten van sociale klassenverschillen. De rol van etniciteit binnen culturele velden is daardoor relatief onderbelicht gebleven (Bennett e.a., 2008; Hall, 1992; Lamont \& Lareau, 1988). Voor ons onderzoek naar de wijze waarop in het culturele veld etnische grenzen worden getrokken en veranderen, maken we daarom ook gebruik van sociologische studies naar ras en etniciteit. Actoren in alle sociale domeinen blijken zich veelvuldig te baseren op etnische classificaties (Brubaker, Loveman \& Stamatov, 2004), omdat deze zeer toegankelijk zijn en geëigend lijken om greep te krijgen op een complexe sociale werkelijkheid (Hale, 2004). Tot dusver is echter nauwelijks onderzoek gedaan naar etnische grenzen in het culturele domein. 
In onze analyse van de loopbaan van etnische minderheidsauteurs spitsen we ons toe op de kritische receptie van hun werk. Via een inhoudsanalyse van de dagbladrecensies van het complete oeuvre van etnische minderheidsschrijvers gaan we na in hoeverre en op welke wijze literaire critici etnische grenzen trekken. Enerzijds kijken we hierbij naar de mate waarin critici verwijzen naar de achtergrond (behorend tot een etnische minderheid of deel uitmakend van de meerderheid) van de auteur die ze bespreken. Anderzijds onderzoeken we in hoeverre critici deze auteur vergelijken met andere schrijvers (etnische minderheids- en/of meerderheidsauteurs). Etnische minderheidsauteurs worden vaak als 'etnisch' geclassificeerd (zie Berkers, 2009b). In de loop van hun carrière kunnen zij echter een dergelijke 'etnische typecasting' ontstijgen. Dit impliceert dat zij niet langer worden gezien als lid van een etnische minderheid maar deel zijn gaan uitmaken van de literaire mainstream (Zuckerman, Kim, Ukanwa \& Von Rittmann, 2003).

Ons onderzoek richt zich op de carrières van auteurs die op verschillende tijdstippen tussen 1983 en 2009 - zijn gedebuteerd (cf. Ekelund \& Börjesson, 2002). Deze opzet stelt ons in staat een onderscheid te maken tussen boundary crossing (assimilatie van etnische minderheidsauteurs in de literaire mainstream op individueel niveau) en boundary shifting (structurele veranderingen in de positie van etnische grenzen binnen het literaire veld, waardoor etnische minderheidsauteurs als groep in de mainstream worden opgenomen) (Zolberg \& Woon, 1999). Wij veronderstellen dat deze processen van grensoverschrijding en -verschuiving variëren naar tijd en plaats, afhankelijk van onder meer de grootte en samenstelling van de etnische minderheidspopulatie en de specifieke eigenschappen van het literaire veld in een samenleving. Daarom vergelijken we in ons onderzoek drie Westerse immigratielanden, over een tijdspanne van 25 jaar: de Verenigde Staten, Nederland en Duitsland. De Verenigde Staten is een traditioneel immigratieland, terwijl in Nederland (ondanks het koloniale verleden) en Duitsland grootschalige arbeidsmigratie ('gastarbeiders') een recenter fenomeen is. De centrale vraagstelling in dit artikel is tweeledig: (i) in hoeverre trekken literaire critici in de Verenigde Staten, Nederland en Duitsland tussen 1983 en 2009 etnische grenzen in hun recensies van etnische 
minderheidsauteurs en (ii) welke veranderingen doen zich voor in hun gebruik van etnische classificaties, in de loop van de carrière van etnische minderheidsauteurs én in de loop van de tijd?

Ons onderzoek is daarmee één van de schaarse longitudinale en crossnationale onderzoeken naar grensverandering (zie ook Bail, 2008; Zhao, 2005). Het literaire veld vormt een interessante casus voor een dergelijk onderzoek. Literatuur geldt als een vorm van 'hoge' cultuur, die echter niet alleen de culturele elite maar ook 'gewone' lezers aanspreekt. De assimilatie van etnische minderheden in een dergelijk invloedrijk en statusvol maatschappelijk domein impliceert de toekenning van symbolische waarde aan zowel de betrokken individuen als aan de tot dan toe buitengesloten groep als geheel. Vanwege het talige karakter van literatuur worden etnische minderheden in het literaire veld echter met een sterkere grens geconfronteerd dan in veel andere domeinen. Wij richten ons in dit onderzoek op dagbladrecensenten omdat hun selecterende en beoordelende activiteiten in grote mate de legitimering van literatuur en de uiteindelijke canonisering van schrijvers bepalen (Rosengren, 1987; Verboord, 2009). Daarnaast claimen critici dat zij vooral zuiver esthetische criteria hanteren in hun waardering van literaire werken, maar buitentekstuele kenmerken - zoals het literaire prestige van de uitgever of het geslacht van de auteur - blijken een vergaande invloed te kunnen hebben op de beoordelingspraktijk van recensenten (Janssen, 1997, 1998; Vogel, 2001). Etniciteit is ook een buitentekstueel kenmerk dat kan meespelen in de kritische receptie van een auteur en zijn of haar werk.

\section{Literaire critici en etnische grenzen}

\subsection{Het literaire veld, literaire critici en esthetische classificaties}

Literaire velden spelen een cruciale rol in de classificatie van literatuur. Binnen deze velden bepalen experts, zoals critici, wat 'goede' literatuur is en wat niet. Het cultureel kapitaal dat vereist is om met succes binnen het literaire veld te functioneren is onevenredig over sociale groepen verdeeld, in het algemeen ten gunste van de traditioneel dominante groepen in de 
samenleving (hogere sociale klassen, mannen, autochtonen). De instituties die bij de productie en verspreiding van cultureel kapitaal zijn betrokken, zoals het onderwijs, zouden de bestaande hiërarchieën in stand houden (Bourdieu \& Passeron (1990 [1970]). Ook het literaire uitgeverijwezen en de literaire kritiek wordt een belangrijke rol toegedicht in de reproductie van sociale ongelijkheid binnen het literaire veld. Recensenten functioneren als poortwachters die bepalen welke boeken en schrijvers tot het domein van de literatuur worden toegelaten (Hirsch, 1972; Dorleijn \& Van Rees, 2006). Tevens kennen zij meer of minder literair prestige (symbolisch kapitaal) toe aan schrijvers en hun werken (Bourdieu, 1993). Critici doen het graag voorkomen dat hun selecties en oordelen primair berusten op zuiver esthetische criteria (Janssen, 2003), maar in de praktijk leunen zij sterk op buitentekstuele informatie om het verloop van een schrijverscarrière te voorspellen of nieuwe literaire werken makkelijker te kunnen classificeren. Ten eerste betreft dit informatie over de veldpositie van auteurs zoals de status van de uitgever (Janssen, 1997), literaire nevenactiviteiten (Janssen, 1998), of connecties met gevestigde auteurs, literaire groeperingen, stromingen of richtingen (Anheier \& Gerhards, 1991; De Nooy, 1991). Ten tweede zijn de achtergrondkenmerken van de auteur van invloed op de selectie en classificatie van critici. Zo dienen potentiële auteurs over voldoende cultureel kapitaal (opleidingsniveau) te beschikken om erkenning te krijgen in het literaire veld. Vrouwelijke auteurs stuiten relatief vaak op barrières wanneer zij carrière willen maken in het (Nederlandse) literaire veld (Vos, 2008) en worden in veel gevallen anders beoordeeld dan hun mannelijke collega's (Vogel, 2001).

Ook etniciteit blijkt een rol te spelen in de selectie en beoordeling van literatuur. Zo maken literaire beleidsmakers (Berkers, 2009a) en samenstellers van literatuurgeschiedenissen (Berkers, 2009b) gebruik van etnische classificaties. Boekrecensies handelen niet alleen over literaire kwaliteit, stijl en thematiek, maar kunnen bovendien informatie over de (etnische) achtergrond van de auteur bevatten (Griswold, 1987). Als 'niet-blank zijn' een ongebruikelijk kenmerk is in een literair veld, is de kans groot dat recensenten hier expliciet aandacht aan 
besteden, vooral als ze veronderstellen dat hun lezers dit van belang achten (ibid.). Afgezien van Griswold's studie is er nauwelijks onderzoek gedaan naar de condities waaronder etnische classificaties prevaleren boven 'zuiver' esthetische classificaties. Hoewel etnische grenzen vaak scherper en stabieler zijn (Lamont, 2000; Levitt, 2005), wordt het cultuursociologische onderzoek vooralsnog gedomineerd door de Bourdieuaanse focus op klassenonderscheidingen. Voor een nader begrip van etnische classificaties in culturele velden wenden wij ons daarom tot de sociologie van ras en etniciteit.

\subsection{Etnische grensverandering}

In aansluiting op het pionierswerk van Fredrik Barth (1969) definiëren de meeste sociologen etniciteit niet langer (exclusief) in termen van gedeelde kenmerken of 'objectieve' culturele overeenkomsten. In plaats daarvan richten ze zich veelal op de vraag hoe etnische grenzen tot stand komen als gevolg van de sociale interactie tussen etnische minderheidsgroepen en de (mainstream) samenleving (Nagel, 1994; Wimmer, 2008). Deze verschuiving van een objectivistische naar een constructivistische benadering van etniciteit heeft geleid tot een groeiende interesse in symbolische in plaats van sociale grenzen. In dit type onderzoek wordt etniciteit gezien als een specifieke manier om de sociale werkelijkheid te zien, te classificeren en te begrijpen (Brubaker, 2009; Hale, 2004). Hoewel dergelijke symbolische grenzen in eerste instantie slechts bestaan op het intersubjectieve niveau, leiden ze bij voldoende consensus vaak tot sociale grenzen, dat wil zeggen, ongelijke toegang tot materiële en immateriële hulpbronnen en kansen (Brubaker e.a., 2004; Lamont \& Molnár, 2002; Zhao, 2005). Etnische minderheidsauteurs zijn dan ook geneigd zich te verzetten tegen etnische classificaties, omdat ze vrezen dat (etnische) typecasting literaire erkenning in de weg kan staan (zie Vullings \& Versloot, 2004). De aanwezigheid van etnische grenzen in dagbladrecensies onderzoeken we hier aan de hand van drie indicatoren: (i) etnische minderheidslabels; (ii) etnische meerderheidslabels; en (iii) vergelijkingen met andere (etnische minderheid of meerderheid) auteurs (zie paragraaf 3.2). 
Onderzoeken naar grensverandering richten zich deels op assimilatie, dat wil zeggen, het proces waarbij etnische classificaties in belang afnemen (Alba, 2005; Alba \& Nee, 2003; Brubaker, 2001). Wij sluiten hierbij aan door een toe- of afname in het gebruik van etnische labels en vergelijkingen met andere auteurs als indicatief te beschouwen voor een verandering in etnische grenzen. Etnische (en andere) classificaties zullen alleen gebruikt worden als ze de overeenkomsten en verschillen tussen mensen en objecten tamelijk accuraat kunnen verklaren (Hale, 2004). Ze nemen in belang af wanneer ze niet langer passen bij de situatie.

Zo lijken etnische classificaties minder op hun plaats naarmate een individuele etnische minderheidsauteur langer actief is in het literaire veld. Wanneer een auteur eenmaal is gedebuteerd, en daarmee een bepaalde mate van literaire erkenning heeft gekregen, zijn critici wellicht minder geneigd om hem of haar als etnisch anders te beschouwen. Dit proces van grensoverschrijding (boundary crossing) komt overeen met de klassieke vorm van assimilatie: een individuele minderheidsauteur wordt opgenomen in de literaire mainstream, zonder dat de grens zelf verandert (zie Zolberg \& Woon, 1999).

Etnische grenzen kunnen ook veranderen los van de fase waarin de carrière van een specifieke auteur zich bevindt. Naarmate in de loop der tijd meer etnische minderheidsauteurs het literaire veld betreden, zouden recensenten de etnische achtergrond steeds minder als iets ongebruikelijks kunnen gaan zien, waardoor ze het niet meer 'gepast' vinden om deze in hun boekrecensie te vermelden. In dit geval worden etnische minderheidsauteurs als groep minder vaak in termen van hun etnische achtergrond geclassificeerd, afhankelijk van het jaar van publicatie, en onafhankelijk van de fase waarin de carrière van de betreffende auteur zich bevindt. Dit proces, waarbij de grens een nieuwe positie inneemt, meestal in de richting van meer insluiting, noemen we grensverschuiving (boundary shifting) (Alba 2005; Zolberg \& Woon, 1999).

Grensveranderingen hangen echter ook samen met veranderingen in de chronische dan wel situationele toegankelijkheid van etnische classificaties. Situationele toegankelijkheid betreft 
de mate waarin classificaties onmiddellijk beschikbaar zijn via de situatie zelf, door middel van direct contact, actieve suggestie of aanwijzingen in de omgeving (Hale, 2004). Zo kunnen literaire critici 'verleid' worden tot het gebruik van etnische - in plaats van esthetische classificaties als de thematiek van een boek gerelateerd is aan de etnische achtergrond van de auteur. Ook kunnen uitgevers dergelijke classificaties actief suggereren door middel van biografische informatie op de boekomslag. Ten slotte zullen recensenten waarschijnlijk eerder gebruik maken van etnische classificaties waneer het werk van een auteur door een etnische minderheidsuitgever is gepubliceerd. Eén en ander impliceert dat etnische minderheidsauteurs en hun uitgevers zelf ook actief kunnen bijdragen aan het verwerven van een plek in de literaire mainstream door etnische classificaties minder toegankelijk te maken. In dit onderzoek zijn we echter voornamelijk geïnteresseerd in assimilatie van minderheidsauteurs door de meerderheid.

Chronische toegankelijkheid betreft de mate waarin bepaalde categorieën beschikbaar zijn via herinnering - los van de specifieke situatie - doordat ze frequent geactiveerd worden (en daarom vers in het geheugen liggen) of er een cognitief verband gelegd kan worden met andere veelgebruikte categorieën (Hale, 2004: 471). Deze vorm van toegankelijkheid sluit aan bij Swidler's (1986) benadering van cultuur als een gereedschapskist (toolkit). Cultuur verschaft actoren de middelen (gereedschap) om hun omgeving te classificeren en daarmee te begrijpen. Hoe frequent bepaald gereedschap wordt gebruikt, hangt onder andere af van de mate waarin het door de verschillende instituties (bijvoorbeeld de natie-staat) is verankerd in ons geheugen (Swidler, 2001). Actoren in sommige samenlevingen (literaire critici incluis) zijn bijvoorbeeld eerder geneigd de omgeving te classificeren in termen van etniciteit (Lamont \& Thévenot, 2000). Het is echter moeilijk voorspelbaar hoe zulke culturele verschillen opduiken in de recensies van het werk van etnische minderheidsauteurs. Zo lieten de Amerikaanse recensenten van de WestIndische auteur George Lamming vanaf de jaren vijftig tot in de jaren zeventig hun obsessie met ras lieten blijken door er voordurend over te schrijven, terwijl de preoccupatie met kolonialisme bij Britse critici leidde tot het vermijden van hetzelfde onderwerp (Griswold, 1987: 1102). De 
chronische toegankelijkheid van etnische classificaties onderzoeken we hier met behulp van een crossnationale vergelijking tussen de Verenigde Staten, Nederland en Duitsland.

\section{Data en methoden}

De mate waarin etnische grenzen zijn veranderd in de literaire velden van de Verenigde Staten, Nederland en Duitsland wordt bestudeerd aan de hand van een kwantitatieve inhoudsanalyse van dagbladrecensies van etnische minderheidsauteurs die tussen 1983 en 2006 hun carrière zijn begonnen.

\subsection{Etnische groepen, auteurs en recensies}

Een loopbaan als literaire schrijver vereist een goede taalbeheersing en het nodige 'cultureel kapitaal,' waarvoor opleidingsniveau de meest gebruikte indicator is (Bourdieu, 1984, 1993). Verschillende etnische groepen vertonen aanzienlijke verschillen in opleidingssucces, afhankelijk van de verschillende immigratietrajecten (zie Van Tubergen \& Kalmijn, 2005). Om zeker te zijn van voldoende crossnationale vergelijkbaarheid is in dit onderzoek daarom voor elk land één bepaalde etnische immigrantengroep (arbeidsimmigranten) in beschouwing genomen met een vergelijkbaar niveau in taalbeheersing en opleiding (cf. Berkers, Janssen \& Verboord, 2010).

In de Verenigde Staten vormt de Mexicaanse minderheid met bijna tien procent van de totale bevolking de grootste arbeidsmigratiegroep. Deze groep scoort lager dan andere minderheidsgroepen voor wat betreft de beheersing van het Engels en het opleidingsniveau (Carliner, 2000). In Nederland lopen taalbeheersing- en opleidingsniveau van de Marokkaanse minderheid - circa twee procent van de bevolking - ver achter op de Nederlandse meerderheid, deels omdat veel Marokkaanse immigranten oorspronkelijk alleen het Berbers spraken, een taal

zonder schrift (Tesser, Merens \& Van Praag, 1999; Tolsma, Coenders \& Lubbers, 2007). In Duitsland vormt de Turkse minderheid verreweg de grootste arbeidsmigratiegroep, met een aanwas van ongeveer 1,5 miljoen in 1980 (2,5 procent van de West-Duitse bevolking) tot 2,5 
miljoen in 2005 (drie procent van de verenigde Duitse bevolking). In vergelijking met de meerderheidsbevolking heeft de Turkse minderheid een veel lager taalbeheersingniveau van het Duits en een lager opleidingsniveau (Dustman, 1994; Worbs, 2003).

Bij ontstentenis van betrouwbare, longitudinale data over de populatie van etnische minderheidsauteurs in elk land, hebben wij gebruik gemaakt van verschillende online databases (Latino Literature) en impressionistische overzichten (Aynan, 2006; Rösch, 2006), om een voorlopige lijst van auteurs samen te stellen die van Mexicaanse (voor de Verenigde Staten), Marokkaanse (voor Nederland) of Turkse (voor Duitsland) afkomst zijn. Vanwege de crossnationale vergelijkbaarheid kwamen daar nog een aantal criteria bij. Ten eerste beperkt dit onderzoek zich tot de 'anderhalf' generatie (diegenen die voor hun dertiende geïmmigreerd zijn) en tweede en derde generatie immigrantenauteurs. Ten tweede worden alleen auteurs meegenomen die in hoofdzaak fictie (romans, korte verhalenbundels, jeugdliteratuur) publiceren. Ten derde houden we er rekening mee dat Turkse minderheidsauteurs in Duitsland hun werk soms in het Turks schrijven en het daarna in het Duits laten vertalen. Dergelijke boeken (en auteurs) tellen niet mee in de analyse omdat zij zich niet in eerste instantie richten op het Duitse literaire veld en dus geen mainstream erkenning nastreven. Ten vierde is de dataverzameling beperkt tot auteurs die in 1980 of later hun prozadebuut publiceerden. Het vijfde en laatste criterium is dat ten minste één boek uit het oeuvre van de auteur in een dagblad is gerecenseerd.

Voor alle auteurs is een overzicht gemaakt van de fictieboeken die zij gedurende hun loopbaan hebben gepubliceerd en van alle dagbladrecensies (van meer dan 100 woorden) die binnen zes maanden na publicatie zijn verschenen. De recensies werden verzameld met behulp van Proquest Historical Newspapers, LexisNexis (de VS); Literom en LexisNexis (Nederland); en Factiva en het Deutsches Literaturarchiv (Duitsland). Zo ontstond er een corpus van 134 Amerikaanse recensies, 127 Nederlandse, en 122 Duitse, allen verschenen tussen 1985 en 2009 (zie Appendix voor een overzicht van de dagbladen waarin deze recensies zijn verschenen). 
Alle andere informatie over individuele auteurs werd verkregen door raadpleging van relevante online databases (Latino Literature, Literature Resource Center), websites (Perlentaucher) en andere bronnen (Aynan, 2006; Rösch, 2006).

[Tabel 1 ongeveer hier]

Het resultaat van deze selectieprocedure staat in tabel 1 . Gezien de relatief lage aantallen van Marokkaans-Nederlandse en Turks-Duitse auteurs die het literaire veld met succes hebben betreden - dus die erin slaagden een boek te publiceren dat ook nog in de dagbladen gerecenseerd werd - zien we een aantal onvermijdelijke verschillen in steekproefgrootte, debuutjaar, debuutleeftijd en gender. Uiteindelijk hebben wij 23 Mexicaans-Amerikaanse auteurs in ons onderzoek betrokken, tegenover 9 Marokkaans-Nederlandse en 11 Turks-Duitse auteurs. Binnen de laatste groep heeft Feridun Zaimoglu verreweg de meeste recensies gekregen. MarokkaansNederlandse auteurs blijken gemiddeld op jongere leeftijd te debuteren (23,6 jaar) dan Mexicaans-Amerikaanse (27,1 jaar) en Turks-Duitse auteurs (36,1 jaar). Verder bevat de Nederlandse steekproef minder vrouwelijke auteurs dan het de Amerikaans en Duitse steekproef. Ondanks deze verschillen hebben bijna alle auteurs een lagere socio-economische achtergrond en hebben ze allemaal een of andere vorm van hoger onderwijs genoten, wat hen het noodzakelijke cultureel kapitaal heeft verschaft om toegang tot het literaire veld te verkrijgen.

\subsection{Afhankelijke variabelen}

De etnische grenzen in dagbladrecensies van etnische minderheidsauteurs zijn geoperationaliseerd met behulp van drie indicatoren (i) etnische minderheidslabels; (ii) etnische meerderheidslabels; en (iii) vergelijkingen met andere (etnische minderheid of meerderheid) auteurs. 
Etnische minderheidslabels. De eerste indicator bevat termen die (a) direct refereren aan de etnische achtergrond van de auteur, bijvoorbeeld doordat de auteur wordt ingedeeld bij een etnische minderheid ('türkischen Autor' of 'the cadre of top-flight Chicana writers'); (b) afkomst of geboorteplaats benoemen ('van Marokkaanse origine' of 'the child of Mexican immigrants'); of (c) expliciet een verband tussen de fictie van de auteur en de werkelijkheid leggen ('takes us to a reality that he knows well - the daily survival of Mexicans living in East Los Angeles'). Niet meegerekend zijn algemene termen die ook gebruikt worden voor niet-etnische minderheden (vreemdelingen, gastarbeiders); verwijzingen naar de taal (met name omdat het Spaans niet exclusief de taal van Mexicaans-Amerikanen is en het Berbers een taal zonder schrift is); en etnische genres die niet alleen naar de etnische achtergrond van een auteur verwijzen maar ook naar literaire stijl.

Etnische meerderheidslabels. Waar etnische minderheidslabels de auteur duidelijk apart zetten als anders, zou de expliciete nadruk op de meerderheid achtergrond van een auteur als een teken van insluiting gezien kunnen worden. Wij beschouwen het expliciete gebruik van meerderheidslabels echter ook als een manier om etnische grenzen te trekken. Zowel de etnische minderheids- als meerderheidslabels 'markeren' etnische minderheidsauteurs immers als afwijkend van de ‘ongemarkeerde' meerderheidsauteurs (Waugh, 1982; Brekhus, 1996).[2] Onze tweede indicator voor etnische grenzen betreft dus het aantal expliciete verwijzingen naar etnische minderheidsauteurs als deel van de meerderheid. Weer geldt dat deze termen (a) direct naar de meerderheidsachtergrond van de auteur verwijzen ('deutsche Schriftstellerin'); (b) de afkomst van een auteur benadrukken, of het land waar hij verblijft ('Nederland, zijn geboorteland' of 'lives in the United States'); of (c) expliciet een verband leggen tussen de fictie van de auteur en de werkelijkheid ('writes about his American experience'). 
Vergelijkingen met andere auteurs. Critici plegen het werk van een auteur te vergelijken met dat van tijdgenoten en voorgangers (Rosengren, 1987). We hebben de vergelijkingen met andere auteurs geteld en ook de namen en etnische achtergrond geregistreerd van alle auteurs met wie de etnische minderheidsauteurs werden vergeleken. Een auteur die overwegend of uitsluitend vergeleken wordt met meerderheidsauteurs is deel gaan uitmaken van de (nationale) literaire mainstream, en wordt niet langer als etnische minderheidsauteur geclassificeerd.[3]

\subsection{Onafhankelijke variabelen}

Voor het toetsen van grensoverschrijding maakten we gebruik van de onafhankelijke variabelen (wel of geen) prozadebuut en het aantal boeken dat een auteur op zijn naam heeft staan.[4] Grensoverschrijding kan een erg abrupt proces zijn dat aan een 'bekering' doet denken (Alba, 2005). In recensies van een eerste boekpublicatie leunen critici wellicht sterker op labels voor een etnische achtergrond dan bij volgende publicaties, omdat andere bruikbare aanknopingspunten voor het schrijven van de recensie (zoals eerdere classificaties door de kritiek of auteursinterviews) ontbreken of minder makkelijk beschikbaar zijn (Janssen, 1997). Debuten vormen daarnaast een bijzonder sterke grens; meer dan volgende publicaties bepalen ze de kans op de toekomstige aandacht in de literaire kritiek (Janssen, 1994; Van Rees \& Vermunt, 1996). Daarom gaan we na of de kans op het gebruik van etnische classificaties inderdaad groter is in het geval van een prozadebuut. Het aantal fictieboeken dat een auteur op zijn naam heeft staan gebruiken we als een indicator van een meer geleidelijk proces van grensoverschrijding, i.e. om vast te stellen of etnische grenzen gaandeweg een literaire carrière veranderen.

De onafhankelijke variabele waarmee grensverschuiving wordt voorspeld is het publicatiejaar van het fictieboek, wat geteld wordt als de leeftijd van het boek in jaren (vanaf 2009). Zo gaan we na of etnische grenzen in de loop der tijd veranderen, los van de etnische achtergrond van een specifieke auteur. 


\subsection{Controlevariabelen}

We gebruiken verschillende controlevariabelen zodat eventuele grensveranderingen op het niveau van het literaire veld, niet vallen te herleiden tot de kenmerken van individuele auteurs, boeken of recensies.

Achtergrond van de auteur. Wij controleren voor de volgende achtergrondkenmerken: leeftijd, geslacht en geboren in het buitenland. De laatste variabele is belangrijk omdat critici de anderhalf generatie etnische minderheidsauteurs - die dus in het buitenland zijn geboren mogelijk eerder in termen van etnische achtergrond zullen classificeren dan tweede generatie auteurs.

Kenmerken van het boek. We controleren hier voor: etnische achtergrond auteur op boekomslag; meerderheidsachtergrond auteur op boekomslag; etnische thematiek in boekinhoud; meerderheidsthematiek in boekinhoud; literair prestige van de uitgever; uitgever van Hispanic literatuur (alleen VS). De informatie op de boekomslag kan ook van invloed zijn op de classificaties van de recensent (Coser, Kadushin \& Powell, 1982). Uitgevers kunnen een boek (of een auteur) als 'etnisch' typeren, ter onderscheiding van andere titels op de markt (Ween, 2003; Young, 2006). Voor literaire critici worden etnische classificaties dan situationeel toegankelijker. Wij controleren daarom voor het aantal etnische minderheids- en meerderheidslabels (cf. de criteria hierboven) op de boekomslag van elke eerste (gebonden) druk van een werk.

Wij gebruiken de boekomslag ook om vast te stellen of een werk zelf etnische en/of meerderheidsthema's aansnijdt. Dat kan ook weer leiden tot het gebruik van etnische classificaties. De informatie op de boekomslag betrof vooral de locatie van het verhaal ("the tale opens in the 1870s in a village in northern Mexico' of 'Kanakas berichten ungeschminkt vom Rande der Deutschen Gesellschaft') en de achtergrond van de hoofdpersonages ('dit boek over Marokkaanse meisjes' of 'Luis J. Rodriguez captures ... a little known era in America's history').

Selecties en classificaties door recensenten worden beïnvloed door het literaire prestige van de uitgever (Coser, Kadushin \& Powell, 1982; Janssen, 1997). Om dit prestige te meten en 
daarbij rekening te houden met mogelijke veranderingen in de loop der tijd, kijken we naar het aantal keren dat de uitgever een prestigieuze literaire prijs heeft gewonnen in de vijf jaar die voorafgingen aan de verschijning van het besproken werk (zie Verboord, 2003), namelijk de Pulitzer Prize fiction en de National Book Award fiction (VS); de AKO literatuurprijs en de Libris literatuurprijs (Nederland); de Bremer Literaturpreis en de Duitstalige Ingeborg-Bachmann-Preis (Duitsland). In het geval van uitgevers die gespecialiseerd zijn in etnische minderheidsfictie zullen de recensenten de auteurs van dat fonds eerder door een 'etnische' lens bespreken. Deze controlevariabele is alleen voor de VS gebruikt, waar verscheidene uitgevers zich hebben gespecialiseerd in Hispanic literatuur, of, nog wat breder, in Chicano literatuur (bijv. Arte Publico Press, Rayo and Bilingual Press). Zij zijn verantwoordelijk voor 22 van de 60 gerecenseerde boeken die door de geselecteerde Mexicaans-Amerikaanse auteurs werden geschreven.

Kenmerken van de recensie. De controlevariabelen hiervoor zijn als volgt: lengte van de recensie (in het aantal woorden); landelijk kwaliteitsdagblad; Hispanic lezerspubliek (alleen VS) en Hispanic recensent (alleen VS). Langere recensies kunnen meer achtergrondlabels en vergelijkingen bevatten. In tegenstelling tot regionale, populaire en/of niche dagbladen, richten landelijke kwaliteitskranten zich uitdrukkelijk op lezers met een hoger (cultureel) opleidingsniveau - en besteden ze in het algemeen meer aandacht aan literatuur (Janssen, 1999; Szántó, Levy \& Tyndall, 2004) in stukken die overwegend door professionele recensenten in dienst bij de krant worden geschreven. Vooral Californische en Texaanse kranten kunnen andere classificaties van Mexicaanse minderheidsauteurs bevatten, vanwege hun relatief omvangrijke Hispanic lezersbestand (zie Appendix). De Amerikaanse kranten hebben bovendien de nodige critici van Hispanic origine in dienst, die de Mexicaanse minderheidsauteurs mogelijk anders classificeren.

\subsection{Methode}


Alle afhankelijke variabelen zijn gemeten als dichotome variabelen, namelijk of recensies wel (1) of niet (0) labels over de etnische minderheidsachtergrond, labels over de meerderheidsachtergrond, en vergelijkingen met etnische minderheidsauteurs bevatten. Logistische regressie vormt daarom de meest geëigende statistische techniek. In de volgende paragraaf worden dan ook de odds ratios (relatieve kansverhoudingen) weergegeven. Relatieve kansverhoudingen groter dan 1 geven aan dat er een positieve relatie is tussen de onafhankelijke en afhankelijke variabelen. Zijn de relatieve kansverhoudingen kleiner dan 1 dan is er een negatief verband tussen de afhankelijke variabele en de kans dat een recensie minderheidslabels of meerderheidslabels bevat. Het bleek niet mogelijk om een logistische regressie analyse uit te voeren voor de derde afhankelijke variabele omdat er weinig vergelijkingen waren met andere etnische minderheidsauteurs. Voor deze variabele presenteren we daarom louter beschrijvende analyses.

\section{Resultaten}

\subsection{De constructie van etnische grenzen}

Het eerste deel van de centrale vraagstelling richt zich op de vraag in hoeverre dagbladrecensenten in de Verenigde Staten, Nederland en Duitsland bij het recenseren van etnische minderheidsauteurs etnische grenzen trekken. Hierbij merken we op dat de gemiddelde recensielengte (aantal woorden) niet significant verschilt tussen de drie landen (VS: $M=632,19$; Nederland: $M=697,72$; Duitsland: $M=647,27)$.

[Tabel 2 ongeveer hier]

Slechts 20 procent van alle Amerikaanse dagbladrecensies bevat minstens één verwijzing naar de etnische achtergrond van de besproken auteur, tegenover 47,2 procent van de Nederlandse en 58,2 procent van de Duitse recensies (tabel 2). Hoewel het totaal aantal etnische 
minderheidslabels in Duitse en Nederlandse recensies niet noemenswaardig verschilt, gebruiken Nederlandse recensenten iets vaker twee of meer verwijzingen naar de etnische achtergrond van een specifieke auteur dan hun Duitse collega's. Duitse recensenten classificeren de Turks-Duitse auteurs als etnisch andere individuen, bijvoorbeeeld in 'die Türkin Emine Sevgi Özdamar' of 'deutsch-türkischer Autor.' Daarentegen classificeren Amerikaanse en Nederlandse recensenten de etnische minderheidsauteurs als behorende bij een etnisch andere groep, zoals in 'one of the premier Latina writers' of 'duokapitein van de Marokkaanse garde.'

In vergelijking tot de etnische minderheidslabels gebruiken de recensenten in alle drie de landen minder vaak labels, die etnische minderheidsauteurs als behorend tot de meerderheid classificeren (tabel 2). Weer bevat een significant lager percentage van de Amerikaanse recensies dergelijke labels, 12,4 procent tegenover 33,1 procent en 41,1 procent van respectievelijk de Nederlandse en Duitse recensies. De meeste van deze labels verwijzen naar het land waar de auteur is opgegroeid. Een expliciete classificatie van etnische minderheidsauteurs als meerderheidsauteurs (zoals in 'deze jonge Nederlandse auteur') komt minder vaak voor in de Amerikaanse dan in de Nederlandse en Duitse recensies. De Duitse recensenten hanteren zulke labels echter alleen om de gevestigde auteurs te classificeren.

Ten slotte vergelijken de Nederlandse recensenten etnische minderheidsauteurs significant vaker met andere auteurs (53,5 procent) dan hun Amerikaanse (29,9 procent) en Duitse collegae (28,6 procent). Als we alleen kijken naar vergelijkingen met andere etnische minderheidsauteurs, zien we geen crossnationale verschillen: circa 30 procent van de recensies bevat zulke vergelijkingen. Als we echter specificeren hoeveel van deze recensies een auteur uitsluitend met andere etnische minderheidsauteurs vergelijken, dan staan Duitse recensies bovenaan (8 van de 10), gevolgd door Amerikaanse (5 van de 12) en Nederlandse (8 van de 19).

Over het geheel genomen vinden we voor Nederland en Duitsland dus sterkere etnische grenzen dan voor de Verenigde Staten. In de volgende paragraaf bestuderen we of deze grenzen in de loop der tijd zijn veranderd, en indien dat het geval is, of we deze veranderingen als 
grensoverschrijdingen of als grensverschuivingen moeten interpreteren, en of er wat dit betreft verschillen bestaan tussen de Amerikaanse, Nederlandse en Duitse literaire critici.

\subsection{Veranderingen in etnische grenzen}

Voordat we de multivariate analyses van grensverandering presenteren, tonen we in tabel 3 het gebruik van alle drie de grensindicatoren gedurende de carrière van een auteur, op het moment van zijn of haar debuut versus latere publicaties (grensoverschrijding), en in de loop der tijd (grensverschuiving).

\section{[ Tabel 3 ongeveer hier]}

Het percentage Amerikaanse dagbladrecensies dat etnische minderheidslabels, meerderheidslabels en etnische minderheidsvergelijkingen bevat, verandert niet significant na het eerste boek of in de loop van de carrière van een Mexicaans-Amerikaanse auteur. Ook zijn er nauwelijks wijzigingen gedurende de bestudeerde tijdsperiode. De etnische grenzen lijken dus niet afhankelijk van de vraag of een auteur gevestigd is dan wel een nieuwkomer in de literaire mainstream, en ook niet van het tijdstip van de publicatie van het boek.

Het percentage Nederlandse recensies met etnische minderheidslabels en vergelijkingen met etnische minderheidsschrijvers neemt af als een auteur meer gevestigd raakt. De daling in het gebruik van meerderheidslabels is niet significant. In de loop der tijd zijn de Nederlandse recensenten bovendien minder etnische classificaties - alle drie de types - gaan gebruiken.

Hoewel debuutboeken meer vergelijkingen genereren met etnische minderheidsauteurs dan volgende publicaties, neemt het percentage Duitse recensies met meerderheidslabels of vergelijkingen met etnische minderheidsauteurs niet af gedurende de carrière van schrijvers. Wel daalt het aantal etnische minderheidslabels in de loop van de tijd. Deze daling kan echter grotendeels toegeschreven worden aan het feit dat recensies van tweede boeken van Duitse 
minderheidsauteurs veel meer verwijzingen naar de etnische achtergrond van de auteur bevatten dan zowel de eerste als latere boekpublicaties. We zien daarnaast geen verschil in het gebruik van zulke labels tussen het debuut en volgende publicaties. Opvallend is verder dat het percentage recensies met etnische minderheidslabels daalt tussen 1985-2000 (van 90 procent tot 50 procent), maar waar een vergelijkbare afname in de Nederlandse recensies nadien doorzet, blijft het gebruik van etnische labels in Duitse recensies stabiel na 2000. Dit wijst er dus op dat Duitse recensenten sterke etnische grenzen blijven trekken, zowel gedurende de carrière van de schrijver als in de loop der tijd.

[Tabel 4 ongeveer hier]

Om de significantie van deze bevindingen te bepalen hebben we een serie logistische regressieanalyses uitgevoerd op het gebruik van etnische minderheidslabels en meerderheidslabels, waarbij we gecontroleerd hebben voor de kenmerken van de auteur, het besproken boek, en de recensie zelf. Tabel 4 presenteert voor elk land het basismodel (model 1) waarin het effect van de variabelen prozadebuut en aantal boeken (grensoverschrijding) en publicatiejaar (grensverschuiving) op het gebruik van etnische minderheidslabels wordt geschat. In het geval van de VS is geen sprake van significante resultaten. Voor Nederland heeft publicatiejaar een significant effect. Oudere boeken (en daarom ook oudere recensies) bevatten vaker verwijzingen naar de etnische achtergrond van een auteur, wat duidt op een proces van grensverschuiving. De etnische grenzen voor Marokkaans-Nederlandse auteurs zijn in de loop der tijd afgezwakt, los van de loopbaanfase (aantal publicaties) waarin individuele schrijvers zich bevinden. Als er dus rekening wordt gehouden met het publicatiejaar, wijzen de data niet op een proces van grensoverschrijding. In Duitsland maken auteurs met hun eerste boekpublicatie in verhouding een kleinere kans op een etnisch label dan met volgende publicaties. Maar de drie onafhankelijke variabelen verklaren slechts 9,2 procent van de variantie in het Duitse model 1. 
Het valt daarom nog te bezien of deze bevindingen standhouden als onze controlevariabelen worden toegevoegd.

Model 2 en 3 introduceren de controlevariabelen voor kenmerken van de auteur, het besproken boek en de recensie zelf. Voor de Amerikaanse minderheidsauteurs vinden we afgaande op model 2 aanwijzingen voor grensoverschrijding. Recensies van eerste publicaties bevatten vaker een verwijzing naar de etnische achtergrond van de auteur. Aangezien het aantal boeken geen invloed uitoefent op het voorkomen van etnische classificaties, lijkt alleen de eerste publicatie als een 'heldere' etnische grens te functioneren. Als Mexicaans-Amerikaanse auteurs die grens eenmaal zijn overgestoken, lijken ze deel geworden van de literaire mainstream. Mannelijke auteurs hebben relatief een kleinere kans om als etnische minderheidsauteur gelabeld te worden dan vrouwelijke auteurs. Verder bevatten langere recensies vaker verwijzingen naar de etnische achtergrond van Mexicaans-Amerikaanse auteurs. Ten slotte is de kans dat de etnische achtergrond van een auteur genoemd wordt kleiner in de landelijke kwaliteitsdagbladen dan in de regionale, populaire en niche dagbladen. Deze effecten blijven significant als we - in model 3 rekening houden met enerzijds een specialisatie in Hispanic literatuur van de uitgever en anderzijds een focus van de krant op een Hispanic publiek of een Hispanic achtergrond van de recensent zelf.

In Nederland heeft alleen het jaar waarin een boek is verschenen en gerecenseerd een blijvend significant effect op de kans dat de etnische achtergrond van een etnische minderheidsauteur wordt genoemd. De verklaarde variantie was in model 1 al behoorlijk groot $(0,408)$, vooral in vergelijking tot de andere landen, en in model 2 is dit nog steeds het geval $(0,528)$. Voor geen van de controlevariabelen wordt een effect gevonden.

Het toevoegen van controlevariabelen voor de Duitse recensies verandert de effecten van aantal boeken en publicatiejaar niet, maar eerste boekpublicaties hebben een geringere kans om in etnische termen gelabeld te worden dan volgende publicaties. Turks-Duitse auteurs lijken aanvankelijk zwakke etnische grenzen te ontmoeten als hun eerste boek gerecenseerd wordt. $\mathrm{Na}$ 
die eerste publicatie wordt het echter moeilijker om opgenomen te worden in de literaire mainstream. In de recensies van volgende publicaties worden de etnische grenzen sterker getrokken. De enige andere factoren die het gebruik van labels beïnvloeden liggen in de kenmerken van de recensie: kortere recensies en besprekingen in de landelijke kwaliteitsdagbladen bevatten minder vaak etnische labels.

[Tabel 5 ongeveer hier]

De resultaten voor de meerderheidslabels worden in tabel 5 gepresenteerd. De basismodellen wijzen slechts in beperkte mate op processen van grensoverschrijding (Duitsland) dan wel grensverschuiving (Nederland en Duitsland). Wanneer we vervolgens de kenmerken van de recensie, het boek en de achtergrond van de auteur modelleren, vinden we geen enkele aanwijzing voor grensverandering in de VS (model 2). Wel blijken recensies minder vaak meerderheidslabels te bevatten wanneer ze korter zijn en in de landelijke kwaliteitsdagbladen verschijnen (en niet in regionale, populaire of niche dagbladen) (model 3). Ook is de kans op classificatie in termen van meerderheidsachtergrond kleiner in dagbladen die zich op een Hispanic lezerspubliek richten, terwijl de kans op etnische minderheidslabels niet verschilt van andere kranten (zie tabel 4).

Wanneer we rekening houden met achtergrondkenmerken verdwijnt voor Nederlandse minderheidsauteurs het positieve effect van publicatiejaar. Kennelijk moet dit effect geheel aan de lengte van de recensie worden toegeschreven: hoe meer ruimte recensenten tot hun beschikking hebben, des te meer zij meerderheidslabels gebruiken. Uiteindelijk vertonen de Nederlandse recensies (als we kijken naar het gebruik van meerderheidslabels) derhalve geen verschuiving naar meer symbolische in- of uitsluiting van etnische minderheidsauteurs.

In Duitsland blijven de recensies van oudere boeken een grotere kans op meerderheidslabels houden, zelfs na controle voor de kenmerken van de achtergrond van de 
auteur, van het boek en van de recensie. Hoewel dit dus enig bewijs voor grensverschuiving levert, moet worden aangetekend dat de verklaarde variantie van het model laag is (18,9 procent).

\section{Conclusie en discussie}

In dit artikel is de aanwezigheid van etnische grenzen in Amerikaanse, Nederlandse en Duitse recensies van het werk van etnische minderheidsauteurs van 1983 tot 2009 onderzocht. Hiertoe analyseerden we het gebruik van verschillende achtergrondlabels (etnische minderheid en/of meerderheid) en vergelijkingen met andere auteurs door boekrecensenten in nationale en regionale kranten. We richtten ons daarbij op minderheidsauteurs uit drie vergelijkbare immigratiegroepen per land: Mexicaans-Amerikaanse auteurs in de VS, Marokkaans-Nederlandse schrijvers in Nederland, en Turks-Duitse auteurs in Duitsland.

Ten eerste blijkt de mate waarin etnische grenzen getrokken worden in literatuurrecensies te verschillen tussen de drie landen. Etnische grenzen zijn relatief zwak in Amerikaanse recensies, matig sterk in Nederlandse besprekingen en sterk in Duitse recensies. De gevonden crossnationale verschillen in het gebruik van labels die refereren aan de achtergrond (minderheid en meerderheid) van een auteur - en in mindere mate de vergelijkingen met andere etnische minderheidsauteurs, ondersteunen deze conclusie overduidelijk. Amerikaanse critici classificeren Mexicaans-Amerikaanse auteurs minder frequent als etnische minderheidsauteurs dan Nederlandse en Duitse recensenten dat doen voor respectievelijk Marokkaanse en Turkse minderheidsauteurs. In tegenstelling tot de Amerikaanse critici in Griswold's studie lijken de recensenten die tussen 1983 en 2009 tweede generatie Mexicaans-Amerikaanse auteurs hebben besproken, minder gepreoccupeerd met ras en etniciteit. Het is mogelijk dat de etnische grenzen duidelijker aanwezig waren in recensies van het werk van eerste en 'anderhalf' generatie Mexicaans-Amerikaanse auteurs.

Binnen onze onderzoekspopulatie hebben we veranderingen in de mate waarin critici etnische grenzen trekken vervolgens proberen te duiden in termen van grensoverschrijding en 
grensverschuiving. In het eerste geval zouden veranderingen in classificatie zich in de loop van de carrière van auteurs voordoen (wat duidt op individuele assimilatie in het veld); in het tweede geval vinden veranderingen plaats in de loop der tijd (wat wijst op de erosie van etnische grenzen op het niveau van het literaire veld). De Amerikaanse recensies geven geen blijk van grensverschuiving, maar wel van grensoverschrijding. De classificaties van MexicaansAmerikaanse auteurs door recensenten vertonen geen significante veranderingen tussen 1983 en 2009. Wel hebben auteurs die net op de markt zijn (debutanten) een veel grotere kans om in termen van hun etnische achtergrond geclassificeerd te worden dan schrijvers die meer dan één boek gepubliceerd hebben. Met andere woorden, als Mexicaans-Amerikaanse auteurs de etnische grens eenmaal overgestoken zijn, worden ze (min of meer) beschouwd als deel van de literaire mainstream. De wijze waarop etnische minderheidsauteurs in de literaire mainstream integreren komt daarmee overeen met de manier waarop minderheden in het algemeen deel gaan uitmaken van de Amerikaanse samenleving. Wanneer de etnische minderheidsauteurs eenmaal het 'literaire burgerschap' hebben verworven, worden ze aanzienlijk minder vaak op basis van hun etnische achtergrond beoordeeld.

Voor Nederlandse minderheidsauteurs zijn de etnische grenzen in de loop der tijd duidelijk verschoven. Het gebruik van etnische minderheidslabels in de recensies van Marokkaans-Nederlandse auteurs neemt tussen 1995 en 2009 significant af, los van het aantal boekpublicaties dat deze auteurs op hun naam hebben staan. Toen ze voor het eerst hun entree maakten in het Nederlandse literaire veld, werden de Marokkaans-Nederlandse auteurs niet geclassificeerd als deeluitmakend van de literaire mainstream. Bijna alle vroege recensies bevatten verwijzingen naar de etnische achtergrond van de auteur. Maar naarmate Nederlandse critici (en hun lezers) meer gewoon raakten aan deze auteurs, zijn de etnische grenzen zwakker geworden - meer nog dan in het geval van de Verenigde Staten. Mogelijk waren etnische classificaties midden en eind jaren negentig zo alomtegenwoordig in de Nederlandse literatuurkritiek omdat ze eenvoudig toegankelijk waren. Niet zozeer door een actieve suggestie 
door uitgevers of door de thematische inhoud van de boeken, maar vooral omdat in die periode veel Marokkaans-Nederlandse auteurs min of meer tegelijk hun opwachting maakten in het literaire veld. De vele verwijzingen naar deze auteurs als groep suggereren dat dit heeft geresulteerd in een accentuation effect (zie Hogg \& Abrams, 1988): de literaire overeenkomsten binnen het werk van Marokkaanse minderheidsauteurs worden dik aangezet, waarbij men afgaat op de gemeenschappelijke etnische achtergrond en niet zozeer op het werk zelf.

In Duitse recensies lopen eerste boekpublicaties minder kans om in etnische termen gelabeld te worden dan volgende publicaties, wat suggereert dat Turks-Duitse auteurs aanvankelijk zwakke etnische grenzen tegenkomen als hun eerste boek wordt besproken. Opvallend genoeg trekken recensenten in hun besprekingen van volgende publicaties juist sterkere etnische grenzen. Dit sluit aan bij wat Labrie (1994) 'negatieve integratie' noemt. 'Duits' pleegt gedefinieerd te worden door wat het niet is, wat er onder meer toe leidde dat de Duitse staat tot voor kort het staatsburgerschap onthield aan een groot aantal Ausländer, waarvan er heel wat in Duitsland geboren zijn (Joppke, 1996). Op eenzelfde manier krijgen de Turks-Duitse auteurs relatief eenvoudig symbolische toegang tot het literaire veld, maar is de kans op een volledige assimilatie veel geringer.

Onze bevindingen geven aan dat eerste publicaties niet alleen een belangrijke rol spelen in de literaire carrière van fictie auteurs, maar ook invloed uitoefenen op de kansen van auteurs om in de literaire mainstream te worden opgenomen. Dit roept echter wel de vraag op hoe etnische classificaties in recensies van eerste publicaties van invloed zijn op verdere classificaties. Verschillende studies suggereren dat typecasting door literaire critici een sterker effect zou kunnen hebben dan de classificatie van uitgevers (Van Rees, 1987). Gezien de relatief kleine omvang van onze steekproef kon dit helaas niet onderzocht worden.

Een ander punt dat nader onderzoek behoeft, is de relatie tussen etnische minderheidslabels en meerderheidslabels. Het gebruik van etnische minderheidslabels bleek positief samen te hangen met de aanwezigheid van meerderheidslabels (hetgeen erop lijkt te 
duiden dat beide labels etnische grenzen trekken). Het gebruik van meerderheidslabels was echter minder goed te voorspellen met behulp van de gekozen onafhankelijke variabelen dan de aanwezigheid van minderheidslabels. De oorzaak kan liggen in het geringe aantal meerderheidslabels. Daardoor is het tevens - net als bij de vergelijkingen met andere auteurs moeilijk om een onderscheid te maken tussen termen die direct verwijzen naar de meerderheidsachtergrond van de auteur - waarbij afkomst of land van verblijf wordt benadrukt en meer impliciete verwijzingen - waarbij er een verband wordt gelegd tussen fictie en werkelijkheid. Ook lijken sommige meerderheidslabels het gevolg van een bewust cognitief proces (bijvoorbeeld wanneer een Turks-Duitse auteur expliciet een Duitse schrijver wordt genoemd), terwijl andere veelal (onbewust) voortvloeien uit recensieconventies (bijvoorbeeld wanneer deze onderdeel zijn van de schrijvers biografie). Een meer kwalitatieve benadering kan mogelijk bijdragen tot een nadere specificatie van het gebruik van meerderheidslabels.

Een andere optie voor vervolgonderzoek is een uitbreiding van de analyse met vergelijkbare meerderheidsauteurs, om zo meer zicht te krijgen op 'the unmarked' (Brekhus, 1998). Met andere woorden, worden hedendaagse meerderheidsauteurs zoals Chuck Palahniuk, Tommy Wieringa of Dietmar Dath expliciet als respectievelijk Amerikaans, Nederlands of Duits geclassificeerd, of functioneren zulke meerderheidsauteurs echt als de ongemarkeerde categorie? 


\section{Noten}

1. Pauwke Berkers is universitair docent aan de Afdeling Kunst- en Cultuurwetenschappen van de Erasmus Universiteit Rotterdam. Susanne Janssen is hoogleraar Sociologie van Media en Cultuur van de Afdelingen Media en Communicatie en Kunst- en Cultuurwetenschappen van de Erasmus Universiteit Rotterdam. Marc Verboord is universitair docent aan de Afdeling Media en Communicatie van de Erasmus Universiteit Rotterdam. Correspondentieadres: Faculteit der Historische en Kunstwetenschappen, Eramus Universiteit Rotterdam, postbus 1738, 3000 DR Rotterdam. E-mail: berkers@fhk.eur.nl.

Dit onderzoek is verricht met behulp van een subsidie van de Nederlandse Organisatie voor Wetenschappelijk Onderzoek als onderdeel van het VICI-project Cultural Classification Systems in Transition (NWO- project 277-45-001). Wij danken de reviewers en redactie van Mens \& Maatschappij voor hun commentaar op eerdere versies van dit artikel en voor hun suggesties voor verbetering.

2. We worden hierin gesteund door het feit dat de mate van gebruik van mindersheid- en meerderheidslabels in dagbladrecensies in alle drie de landen een duidelijke positieve samenhang vertoont, namelijk: VS: gamma $=0.809, p<0.001$; Nederland: gamma $=0.759$, $p<0.001$; Duitsland: gamma $=0.750, p<0.001$. Een analyse van de recensies van de eerste en tweede romans van een viertal 'autochtone' auteurs (Arnon Grünberg, Raoul de Jong, Thomas van Aalten, Tommy Wieringa) levert nauwelijks verwijzingen op naar hun Nederlandse achtergrond.

3. De correlatie tussen het aantal vergelijkingen met etnische minderheidauteurs en het totaal aantal etnische minderheidslabels bleek positief te zijn, maar alleen voor de Nederlandse recensies significant (VS: gamma $=0.400$, n.s.; Nederland: gamma $=0.615, p<0.001$; Duitsland: gamma $=0.167$, n.s.)

4. De bivariate correlaties in de Verenigde Staten $(r=-0.562, p<0.001)$, Nederland $(r=-0.609$, $p<0.001)$ en Duitsland $(r=-0.714, p<0.001)$ zijn sterk, wat suggereert dat beide variabelen 
een gelijksoortig concept meten. De toetsen op multicollineariteit laten echter zien dat de intercorrelaties tussen beide variabelen acceptabel zijn en dat ze dus in onze logistische regressiemodellen kunnen worden opgenomen.

\section{Literatuur}

Alba, R. (2005). Bright vs. blurred boundaries. Second-generation assimilation and exclusion in France, Germany, and the United States. Ethnic and Racial Studies, 28(1), 20-49.

Alba, R. \& Nee, V. (2003). Remaking the American mainstream. Assimilation and contemporary Immigration. Cambridge, MA: Harvard University Press.

Anheier, H. \& Gerhards, J. (1991). The acknowledgement of literary influence. Sociological Forum, 6, 137-156.

Aynan, A. (2006). Who's who van de Marokkaanse woordkunstenaars. Passionate, 2(13), 6-10.

Bail, C. A. (2008). The configuration of symbolic boundaries against immigrants in Europe. American Sociological Review, 73, 37-59.

Bakker, P. (2009). Communicatiekaart van Nederland. Overzicht van media en communicatie. Amsterdam: Kluwer.

Barth, F. (1969). Ethnic groups and boundaries. The social organization of culture difference. London: Allen \& Unwin.

Baumann, S. (2001). Intellectualization and art world development. Film in the United States. American Sociological Review, 66(3), 404-426.

Baumann, S., Dowd, T. \& Janssen. S. (Red.). (2009). Introduction. Classifying culture: Agents, structures, processes. Poetics, 37(4), 295-297.

Benson, R. (2006). News media as a 'journalistic field'. What Bourdieu adds to new institutionalism, and vice versa. Political Communication, 23, 187-202.

Bennett, T., Savage, M., Silva, E., Warde, A., Gayo-Cal, M., \& Wright, D. (2008). Culture, class, 
distinction. London: Routledge.

Berkers, P. (2009a). Ethnic boundaries in American, Dutch and German national literary policies, 1965-2005. International Journal of Cultural Policy, 15, 33-50.

Berkers, P. (2009b). Ethnic boundaries in national literary histories. Classification of ethnic minority

fiction authors in American, Dutch and German anthologies and literary history books, 1978-2006. Poetics, 37(5-6), 419-438.

Berkers, P., Janssen, S. \& Verboord, S. (2010). Globalization and ethnic diversity in Western newspaper coverage of literary authors. Comparing developments in France, Germany, the Netherlands, and the United States, 1955-2005. American Behavioral Scientist, 53.

Bourdieu, P. (1984 [1979]). Distinction. A social critique of the judgement of taste. London: Routledge.

Bourdieu, P. (1993). The field of cultural production. Essays on art and literature. Cambridge, UK:

Polity Press.

Bourdieu, P. \& Passeron, J. (1990 [1970]). Reproduction in education, society and culture. London: Sage Publications.

Brekhus, W. (1996). Social marking and the mental coloring of identity. Sexual identity construction and maintenance in the United States. Sociological Forum, 11(3), 497-522.

Brekhus, W. (1998). A sociology of the unmarked. Redirecting our focus. Sociological Theory, $16(1)$ $34-51$.

Brubaker, R. (2001). The return of assimilation? Changing perspectives on immigration and its sequels

in France, Germany, and the United States. Ethnic and Racial Studies, 24(4), 531-548. 
Brubaker, R. (2009). Ethnicity, race and nationalism. Annual Review of Sociology, 35, 21-42.

Brubaker, R., Loveman, M. \& Stamatov, P. (2004). Ethnicity as cognition. Theory and Society, $33,31-$

64.

Carliner, G. (2000). The language ability of U.S. immigrants. Assimilation and cohort effects. International Migration Review, 34(1), 158-182.

Coser, L. A., Kadushin, C. \& Powell, W. W. (1982). Books. The culture and commerce of publishing.

Chicago, IL: University of Chicago Press.

DiMaggio, P. J. (1987). Classification in art. American Sociological Review, 52(4), 440-455.

Dorleijn, G. \& Van Rees, K. (red.) (2006). De productie van literatuur. Het literaire veld in Nederland 1800-2000. Nijmegen: Vantilt.

Dustmann, C. (1994). Speaking fluency, writing fluency and earnings of migrants. Journal of Population Economics, 7, 133-156.

Eijck, K. van, Haan, J. de \& Knulst, W. (2002). Snobbisme hoeft niet meer. De interesse in hoge cultuur is een smaakdemocratie. Mens \& Maatschappij, 77(2), 153-177.

Ekelund, B. \& Börjesson, M. (2002). The shape of the literary career. An analysis of publishing trajectories. Poetics, 30, 341-364.

Esser, F. (1999). 'Tabliodization of the news. A comparative analysis of Anglo-American and German

Press journalism. European Journal of Communication, 14, 291-324.

Griswold, W. (1987). The fabrication of meaning. Literary interpretation in the United States, Great

Britain, and the West Indies. American Journal of Sociology, 92(5), 1077-1117.

Hale, H. E. (2004). Explaining ethnicity. Comparative Political Studies, 37(4), 458-485. 
Hall, J. R. (1992). The capital(s) of cultures. A nonholistic approach to status situations, class, gender, and ethnicity. In M. Lamont \& M. Fournier (Red.), Cultivating differences: Symbolic boundaries and the making of inequality (pp. 257-285). Chicago, IL: Chicago University Press.

Hirsch, P. (1972). Processing fads and fashions. An organization-set analysis of cultural industry systems. American Journal of Sociology, 77(4), 639-659.

Hogg, M. A. \& Abrams, D. (1988). Social identifications. A social psychology of intergroup relations and group processes. London: Routledge.

Janssen, S. (1994). In het licht van de kritiek. Variaties en patronen in de aandacht van de literatuurkritiek voor literaire auteurs en hun werken. Hilversum: Verloren.

Janssen, S. (1997). Reviewing as social practice. Institutional constraints on critics' attention for contemporary fiction. Poetics, 24, 275-297.

Janssen, S. (1998). Side-roads to success. The effect of sideline activities on the status of writers. Poetics, 25, 265-280.

Janssen, S. (1999). Art journalism and cultural change. The coverage of the arts in Dutch newspapers

1965-1990. Poetics, 26, 329-348.

Janssen, S. (2003). Kunstjournalisten in de kijker. Een onderzoek naar de achtergrondkenmerken, beroepspraktijk en professionele opvattingen van kunstmedewerkers van Nederlandse dag- en weekbladen. Boekman., 15(57), 15-26.

Joppke, C. (1996). Multiculturalism and immigration. A comparison of the United States, Germany, and Great Britain. Theory and Society, 25(4), 449-500. 
Labrie, A. (1994). Kultur and Zivilisation in Germany during the nineteenth century. Yearbook of European Studies, 7, 95-120.

Lamont, M. (2000). Meaning-making in cultural sociology. Broadening our agenda. Contemporary

Sociology, 29(4), 602-607.

Lamont, M. \& Lareau, A. (1988). Cultural capital. Allusions, gaps and glissandos in recent theoretical developments. Sociological Theory, 6(2), 153-168.

Lamont, M. \& Molnár, V. (2002). The study of boundaries in the social sciences. Annual Review of Sociology, 28(1), 167-195.

Lamont, M. \& Thévenot, L. (Red.) (2000). Rethinking comparative cultural sociology. Repertoires of

evaluation in France and the United States. Cambrdige, MA: Cambridge University Press.

Levitt, P. (2005). Building bridges. What migration scholarship and cultural sociology have to say to

each other. Poetics, 33, 49-62.

Nagel, J. (1994). Constructing ethnicity. Creating and recreating ethnic identity and culture. Social

Problems, 41(1), 152-176.

Nooy, W. de (1991). Social networks and classification in literature. Poetics, 20, 507-537.

Rees, K. van (1987). How reviewers reach consensus on the value of literary works. Poetics, 16, 275-

294. 
Rees, K. van \& Vermunt, J. (1996). Event history analysis of authors' reputation: Effects of critics'

attention on debutants' careers. Poetics, 23, 317-333.

Roose, H. \& Waege, H. (2003). Van passant tot connaisseur. Een empirische studie over de interne gelaagdheid en de esthetische verwachtingen van het hedendaagse theaterpubliek. Mens \& Maatschappij, 78(3), 242-263.

Rösch, H. (2006). Kurzporträts und Veröffentlichung von und zu Autorinnen der deutschsprachigen Migrationsliteratur. Available from: www2.tu-berlin.de/fak1/el/board.cgi?id=fadi\&action=download\&gul=36.

Rosengren, K. E. (1987). Literary criticism. Future invented. Poetics, 16, 295-325.

Schönbach, K. (1987). The role of mass media in West German election campaigns. Legislative Studies Quarterly, 12(3), 373-394.

Swidler, A. (1986). Culture in action. American Sociological Review, 51, 273-286.

Swidler, A. (2001). Talk of love. How culture matters. Chicago, IL: University of Chicago Press.

Szántó, A., Levy, D. S. \& Tyndall, S. (Red.). (2004). Reporting the arts II. News coverage of arts and

culture in America. New York: National Arts and Journalism Program/Columbia University.

Tesser, P., Merens, J. \& Praag, C. van. (1999). Rapportage minderheden 1999. Den Haag: Sociaal Cultureel Planbureau.

Tolsman, J., Coenders, M. \& Lubbers, M. (2007). De onderwijskansen van allochtone en autochtone Nederlanders vergeleken. Een cohort design. Mens \& Maatschappij, 82(2), $133-154$.

Tubergen, F. van \& Kalmijn, M. (2005). Destination-language proficiency in cross-national perspective. A study of immigrant groups in nine Western countries. American Journal of Sociology, 110(5), 1412-1457. 
U.S. Bureau of the Census. (2000). Summary Files. Government Printing Office.

Verboord, M. (2003). Classification of authors by literary prestige. Poetics, 31, 259-281.

Verboord, M. (2009). The legitimacy of book critics in the age of the internet and omnivorousness:

Expert critics, internet critics and peer critics in Flanders and the Netherlands. European Sociological Review. Available online at:

http://esr.oxfordjournals.org/cgi/content/abstract/jcp039v1.

Vogel, M. (2001). Baard boven baard. Over het Nederlandse literaire en maatschappelijke leven, 1945-1960. Amsterdam: Van Gennep.

Vos, L. (2008). Uitzondering op de regel. De positie van vrouwelijke auteurs in het naoorlogse Nederlandse literaire veld. Proefschrift Rijksuniversiteit Groningen.

Vullings, J. \& Versloot, A. (2004). 'Die godverdomde allochtoniciteit.' Trouw, 31 januari 2004.

Waugh, L. (1982). Marked and unmarked. A choice between unequals in semiotic structure. Semiotica, 38, 299-318.

Ween, L. (2003). This is your book. Marketing America to itself. PLMA, 118(1), 90-102.

Wimmer, A. (2008). The making and unmaking of ethnic boundaries. A multilevel process theory.

American Journal of Sociology, 113(4), 970-1022.

Worbs, S. (2003). The second generation in Germany. Between school and labor market. International

Migration Review 37(4), 1011-1038.

Young, J. K. (2006). Black writers, white publishers. Marketplace politics in twentieth-century. Jackson, MS: University of Mississippi Press.

Zhao, W. (2005). Understanding classifications. Empirical evidence from the American and French wine industries. Poetics, 33, 179-200. 
Zolberg, A. \& Woon, L. L. (1999). Why Islam is like Spanish? Cultural incorporation in Europe and the United States. Politics and Society, 27(1), 5-38.

Zuckerman, E. W., Kim, T., Ukanwa, K. \& Rittmann, J. von (2001). Robust identities or nonentities.

Typecasting in the feature-film labor market. American Journal of Sociology, 108(5), 1018-1074. 


\section{TABELLEN EN Figuren}

Tabel 1 Achtergrondkenmerken en recensieaantallen van de geselecteerde Mexicaans-Amerikaanse, Marokkaans-Nederlandse en Turks-Duitse auteurs

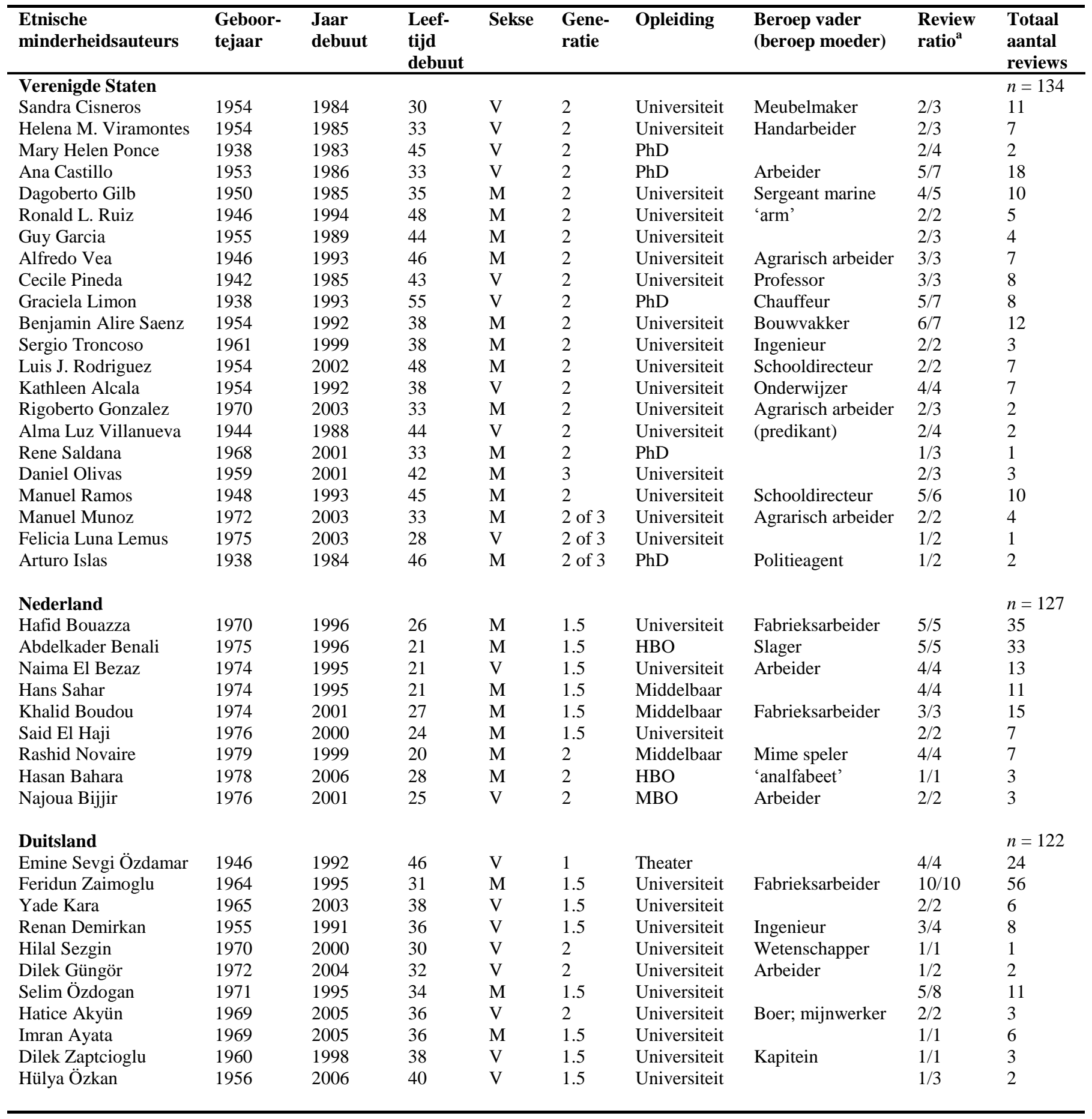

a Het aantal fictie boeken uit het oeuvre van de betreffende auteur dat tenminste één maal gerecenseerd is. 
Tabel 2 Etnische minderheidslabels, meerderheidslabels en vergelijkingen met andere auteurs in literaire recensies in Amerikaanse, Nederlandse en Duitse kranten

\begin{tabular}{llll}
\hline & VS & Nederland & Duitsland \\
\hline Totaal recensies met etnische minderheidslabels & $20,3 \%(31)^{\mathrm{a}}$ & $47,2 \%(60)$ & $58,2 \%(71)$ \\
\hline Eén etnische minderheidslabel & $(15)$ & $(28)$ & $(43)$ \\
Twee of meer etnische minderheidslabels & $(16)$ & $(32)$ & $(28)$ \\
\hline & & & $41,1 \%(53)$ \\
\hline Totaal recensies met etnische meerderheidslabels & $12,4 \%(19)^{\mathrm{a}}$ & $33,1 \%(42)$ & $(31)$ \\
\hline Eén meerderheidslabel & $(14)$ & $(25)$ & $(22)$ \\
\hline
\end{tabular}

\begin{tabular}{llll}
\hline Totaal recensies met vergelijkingen andere auteurs & $29,9 \%(40)$ & $53,5 \%(68)^{\mathrm{b}}$ & $28,6 \%(35)$ \\
\hline $\begin{array}{l}\text { Recensies met vergelijkingen met etnische } \\
\text { minderheidsauteurs }\end{array}$ & $30,0 \%(12)$ & $27,9 \%(19)$ & $28,6 \%(10)$ \\
\hline $\begin{array}{l}\text { Recensies met enkel vergelijkingen met etnische } \\
\text { minderheidsauteurs }\end{array}$ & $(5)$ & $(8)$ & $(8)$ \\
\hline
\end{tabular}

a Verschil tussen zowel Amerikaanse en Nederlandse als Amerikaanse en Duitse recensies is statistisch significant $(p<0,001)$.

b Verschil tussen zowel Nederlands en Amerikaanse als Nederlandse en Duitse recensies in statistisch significant $(p<0,001)$. 
Tabel 3 Percentage recensies per land dat minderheidslabels, meerderheidslabels en vergelijkingen met etnische minderheidsauteurs bevat naar prozadebuut, aantal boeken en periode

\begin{tabular}{|c|c|c|c|c|c|c|c|c|c|c|c|c|c|c|c|c|c|c|}
\hline \multirow[t]{2}{*}{ Land } & \multirow[t]{2}{*}{ Indicator } & \multicolumn{3}{|c|}{ Prozadebuut } & \multicolumn{7}{|c|}{ Aantal boeken } & \multicolumn{7}{|c|}{ Periode } \\
\hline & & Debuut & $\begin{array}{l}\text { Niet } \\
\text { debuut }\end{array}$ & Sig. & 1 & 2 & 3 & 4 & 5 & $\begin{array}{l}6 \text { of } \\
\text { meer }\end{array}$ & Sig. & $\begin{array}{l}1985- \\
1994\end{array}$ & $\begin{array}{l}1995- \\
1997\end{array}$ & $\begin{array}{l}1998- \\
2000\end{array}$ & $\begin{array}{l}2001- \\
2003\end{array}$ & $\begin{array}{l}2004- \\
2006\end{array}$ & $\begin{array}{l}2007- \\
2009\end{array}$ & Sig \\
\hline \multirow[t]{3}{*}{ VS } & Minderheidslabels & 29,2 & 21,8 & n.s. & 29,2 & 16,7 & 21,2 & 25,0 & 18,2 & 41,7 & n.s. & 20,5 & 16,0 & 27,3 & 27,6 & 20,0 & 40,0 & n.s. \\
\hline & Meerderheidslabels & 8,3 & 15,5 & n.s. & 8,3 & 16,7 & 9,1 & 25,0 & 9,1 & 25,0 & n.s. & 18,2 & 12,0 & 0 & 17,2 & 6,7 & 20,0 & n.s. \\
\hline & Vergelijkingen & 8,3 & 9,1 & n.s. & 8,3 & 9,5 & 15,2 & 0 & 0 & 8,3 & n.s. & 13,6 & 12,0 & 0 & 6,9 & 6,7 & 0 & n.s. \\
\hline \multirow[t]{3}{*}{ NL } & Minderheidslabels & 71,9 & 38,9 & $* *$ & 71,9 & 64,7 & 25,9 & 28,6 & 15,4 & - & $* * *$ & - & 93,8 & 78,9 & 59,5 & 9,4 & 21,7 & $* * *$ \\
\hline & Meerderheidslabels & 40,6 & 30,5 & n.s. & 40,6 & 38,2 & 37,0 & 19,0 & 15,4 & - & n.s. & - & 43,8 & 57,9 & 43,2 & 12,5 & 17,4 & $* *$ \\
\hline & Vergelijkingen & 31,3 & 9,5 & $* *$ & 31,2 & 20,6 & 7,4 & 0 & 0 & - & $* *$ & - & 25,0 & 15,8 & 27,0 & 3,1 & 4,3 & $*$ \\
\hline \multirow[t]{3}{*}{$\mathbf{D L}$} & Minderheidslabels & 41,7 & 62,2 & n.s. & 41,7 & 93,3 & 57,1 & 66,7 & 50,0 & 55,3 & $*$ & 86,7 & 66,7 & 48,1 & 55,0 & 57,6 & 54,2 & n.s. \\
\hline & Meerderheidslabels & 45,8 & 42,9 & n.s. & 45,8 & 40,0 & 42,9 & 33,0 & 30,0 & 48,9 & n.s. & 66,7 & 66,7 & 33,3 & 35,0 & 48,5 & 37,5 & n.s. \\
\hline & Vergelijkingen & 20,8 & 5,1 & $*$ & 20,8 & 6,7 & 0 & 8,3 & 0 & 6,4 & n.s. & 6,7 & 0 & 3,7 & 5,0 & 18,2 & 4,2 & n.s. \\
\hline
\end{tabular}

$*=p<0,05 ; * * p<0,01 ; * * *=p<0,001$ (Monte Carlo schattingen chi-kwadraattoets) 
Tabel 4 Logistische regressie analyses (odds ratios) voor de effecten van grensoverschrijding en grensverschuiving op de kans dat de etnische achtergrond van een etnische minderheidsauteur genoemd wordt in een recensie in Amerikaanse, Nederlandse en Duitse kranten

\begin{tabular}{|c|c|c|c|c|c|c|c|}
\hline & $\begin{array}{l}\text { Model } 1 \\
\text { VS }\end{array}$ & $\begin{array}{l}\text { Model } 2 \\
\text { VS }\end{array}$ & $\begin{array}{l}\text { Model } 3 \\
\text { VS }\end{array}$ & $\begin{array}{l}\text { Model } 1 \\
\text { NL }\end{array}$ & $\begin{array}{l}\text { Model } \\
\text { NL }\end{array}$ & $\begin{array}{l}\text { Model } 1 \\
\text { DL }\end{array}$ & $\begin{array}{l}\text { Model } 2 \\
\text { DL }\end{array}$ \\
\hline \multicolumn{8}{|l|}{ Grensoverschrijding } \\
\hline Prozadebuut & 2,735 & $9,186^{*}$ & $8,751 *$ & 0,924 & 0,208 & $0,230 *$ & $0,118 *$ \\
\hline Aantal boeken & 1,260 & 1,623 & 1,801 & 0,979 & 1,961 & 0,908 & 0,852 \\
\hline \multicolumn{8}{|l|}{ Grensverschuiving } \\
\hline Publicatiejaar (leeftijd boek) & 0,983 & 1,049 & 1,099 & $1,435 * * *$ & $1,790 * * *$ & 1,053 & 1,082 \\
\hline \multicolumn{8}{|l|}{ Achtergrond van de auteur } \\
\hline Leeftijd (geboortejaar) & & 1,076 & 1,098 & & 1,039 & & 1,088 \\
\hline Geboren in het buitenland & & - & - & & 0,230 & & 1,637 \\
\hline Geslacht (man) & & $0,233 *$ & $0,220 *$ & & 0,429 & & 0,234 \\
\hline \multicolumn{8}{|l|}{ Kenmerken van het boek } \\
\hline Etnische achtergrond auteur op boekomslag & & 2,204 & 2,195 & & 3,885 & & 1,080 \\
\hline Meerderheidsachtergrond auteur op boekomslag & & 3,579 & 3,393 & & 0,650 & & 1,201 \\
\hline Etnische thematiek in boekinhoud & & 0,969 & 0,945 & & 1,249 & & 0,892 \\
\hline Meerderheidsthematiek in boekinhoud & & 0,753 & 0,812 & & 1,222 & & 1,027 \\
\hline Literair prestige van de uitgever & & 0,083 & 0,091 & & 0,502 & & 2,422 \\
\hline Uitgever van Hispanic literatuur (VS) & & & 1,771 & & & & \\
\hline \multicolumn{8}{|l|}{ Kenmerken van de recensie } \\
\hline Lengte van de recensie & & $1,004 * *$ & $1,004 * *$ & & 1,002 & & $1,002 * *$ \\
\hline Landelijk kwaliteitsdagblad & & $0,059 * * *$ & $0,039 * *$ & & 0,337 & & $0,372 *$ \\
\hline Hispanic lezerspubliek (VS) & & & 0,517 & & & & \\
\hline Hispanic recensent (VS) & & & 2,090 & & & & \\
\hline$\chi^{2}$ & 3,7 & 47,9 & 50,7 & 46,3 & 64,0 & 8,6 & 29,2 \\
\hline Nagelkerke $\mathrm{R}^{2}$ & 0,041 & 0,455 & 0,476 & 0,408 & 0,528 & 0,092 & 0,289 \\
\hline $\mathrm{N}$ & 134 & 134 & 134 & 127 & 127 & 122 & 122 \\
\hline
\end{tabular}

$*=p<0,05 ; * * p<0,01 ; * * *=p<0,001$ 
Tabel 5 Logistische regressie analyses (odds ratios) voor de effecten van grensoverschrijding en grensverschuiving op de kans dat de meerderheidsachtergrond van een etnische minderheidsauteur genoemd wordt in een recensie in Amerikaanse, Nederlandse en Duitse kranten

\begin{tabular}{|c|c|c|c|c|c|c|c|}
\hline & $\begin{array}{l}\text { Model } 1 \\
\text { VS }\end{array}$ & $\begin{array}{l}\text { Model } 2 \\
\text { VS }\end{array}$ & $\begin{array}{l}\text { Model } 3 \\
\text { VS }\end{array}$ & $\begin{array}{l}\text { Model 1 } \\
\text { NL }\end{array}$ & $\begin{array}{l}\text { Model } 2 \\
\text { NL }\end{array}$ & $\begin{array}{l}\text { Model } 1 \\
\text { DL }\end{array}$ & $\begin{array}{l}\text { Model 2 } \\
\text { DL }\end{array}$ \\
\hline \multicolumn{8}{|l|}{ Grensoverschrijding } \\
\hline Prozadebuut & 0,777 & 1,405 & 0,625 & 0,655 & 1,074 & 2,677 & 2,586 \\
\hline Aantal boeken & 1,339 & 1,581 & 2,227 & 1,002 & 1,061 & $1,315^{*}$ & 1,395 \\
\hline \multicolumn{8}{|l|}{ Grensverschuiving } \\
\hline Publicatiejaar (leeftijd boek) & 1,073 & 1,122 & 1,237 & $1,198^{*}$ & 1,174 & $1,163^{*}$ & $1,278^{*}$ \\
\hline \multicolumn{8}{|l|}{ Achtergrond van de auteur } \\
\hline Leeftijd (geboortejaar) & & 0,989 & 1,000 & & 0,985 & & 1,097 \\
\hline Geboren in het buitenland & & - & - & & 0,830 & & 1,901 \\
\hline Geslacht (man) & & 0,903 & 3,113 & & 2,818 & & 0,323 \\
\hline \multicolumn{8}{|l|}{ Kenmerken van het boek } \\
\hline Etnische achtergrond auteur op boekomslag & & 2,727 & 2,916 & & 0,824 & & 2,039 \\
\hline Meerderheidsachtergrond auteur op boekomslag & & 2,297 & 2,466 & & 0,824 & & 0,595 \\
\hline Etnische thematiek in boekinhoud & & 1,140 & 1,153 & & 2,439 & & 0,864 \\
\hline Meerderheidsthematiek in boekinhoud & & 0,613 & 0,695 & & 0,374 & & 1,140 \\
\hline Literair prestige van de uitgever & & 0,138 & 0,163 & & 0,779 & & 2,445 \\
\hline Uitgever van Hispanic literatuur (VS) & & & 4,664 & & & & \\
\hline \multicolumn{8}{|l|}{ Kenmerken van de recensie } \\
\hline Lengte van de recensie & & $1,005 * * *$ & $1,008 * * *$ & & $1,003 * * *$ & & 1,001 \\
\hline Landelijk kwaliteitsdagblad & & 0,397 & $0,035^{* *}$ & & 0,445 & & 0,901 \\
\hline Hispanic lezerspubliek (VS) & & & $0,058^{* *}$ & & & & \\
\hline Hispanic recensent (VS) & & & 0,260 & & & & \\
\hline$\chi^{2}$ & 3,0 & 29,0 & 40,4 & 11,8 & 35,8 & 8,0 & 18,6 \\
\hline Nagelkerke $\mathrm{R}^{2}$ & 0,040 & 0,348 & 0,467 & 0,124 & 0,342 & 0,085 & 0,189 \\
\hline $\mathrm{N}$ & 134 & 134 & 134 & 127 & 127 & 122 & 122 \\
\hline
\end{tabular}

$*=p<0,05 ; * * p<0,01 ; * * *=p<0,001$ 


\section{Appendix: Dagbladen}

\section{Dagbladen waarin de geanalyseerde recensies zijn verschenen:}

\section{Verenigde Staten}

Los Angeles Times (28), Washington Post (20), New York Times (18), El Paso Times (12), San Antonio ExpressNews (8), Denver Post/Rocky Mountain News (7), Houston Chronicle (6), Dallas Morning News (5), San Francisco Chronicle (4), San Diego Union Tribune (4), Santa Fe New Mexican (3), Austin American-Statesman (3), Boston Globe (2), Chicago Sun-Times (2), Milwaukee Sentinel (2), Albuquerque Journal (2), Sunday Oregonian (2), USA Today (1), Boston Herald (1), Seattle Times/Seattle Post-Intelligencer (1), Los Angeles Daily News (1), Tulsa World, Deseret News (1) en identieke recensies die in meer dan één krant verschenen (1).

\section{Nederland}

De Volkskrant (23), NRC Handelsblad (20), Trouw (15), Parool (12), Leeuwarder Courant (8), Algemeen Dagblad (7), Telegraaf (6), Haarlems Dagblad (5), Nederlands Dagblad (4), Financiële Dagblad (3), Dagblad van het Noorden (3), Haagsche Courant (3), Eindhovens Dagblad (3), De Gelderlander (2), Noordhollands Dagblad (2), BN/De Stem (1), Stentor (1), PZC (1), Rijn en Gouwe (1), Rotterdams Dagblad (1), Brabants Dagblad (1), De Limburger (1) en identieke recensies die in meer dan één krant verschenen (4).

\section{Duitsland}

Frankfurter Allgemeine Zeitung (19), Süddeutsche Zeitung (15), Die Tageszeitung (12), Neues Deutschland (11), Frankfurter Rundschau (9), Der Tagessiepiegel (8), weekkrant Die Zeit (8), Stuttgarter Zeitung (6), Berliner Zeitung (6), Die Welt (6), Nürnberger Nachrichten (5), Badische Zeitung (4), Rheinische Post (2), Hamburger Abendblatt (2), Berliner Morgenpost (2), Financial Times Deutschland (1), Märkische Allgemeine (1), Schwäbische Zeitung (1), Esslinger Zeitung (1), Schwäbisches Tagblatt (1), Wiesbadener Kurier (1) en Müncher Merkur (1). 
Dabladen die gecodeerd zijn als nationale of supra-regionale kwaliteitskranten:

\section{Verenigde Staten}

New York Times en de Washington Post (Benson, 2006).

\section{Nederland}

De Volkskrant, NRC Handelsblad, Trouw, Het Parool (Bakker, 2007).

\section{Duitsland}

De Frankfurter Allgemeine Zeitung, de Süddeutsche Zeitung, die Tageszeitung, de Frankfurter Rundschau, die Welt, en weekkrant die Zeit (Schönbach, 1987; Esser, 1999).

\section{Amerikaanse kranten met een omvangrijk Hispanic lezerspubliek}

Data over het Hispanic lezerspubliek zijn helaas niet beschikbaar voor alle dagbladen in onze steekproef. Echter, de data die voorhanden is, suggereert een sterke samenhang tussen een Hispanic lezerpubliek en de grootte van de Hispanic populatie in een bepaalde staat (Benson, 2006; U.S. Bureau of the Census, 2000). De volgende Californische (Los Angeles Times, San Francisco Chronicle, San Diego Union Tribune, Los Angeles Daily News), New Mexicaanse (Santa Fe New Mexican, Albuquerque Journal) en Texaanse dagbladen (El Paso Times, San Antonio Express-News, Houston Chronicle, Dallas Morning News, Austin American-Statesman) zijn daarom gecodeerd als kranten die zeer waarschijnlijk een groot Hispanic lezerspubliek hebben. 